\title{
On-lay lamellar keratoplasty for the treatment of keratoconus
}

\author{
MARGUERITE B. McDONALD, STEVEN B. KOENIG, ARAN SAFIR, AND \\ HERBERT E. KAUFMAN \\ From the Lions Eye Research Laboratories, LSU Eye Center, Louisiana State University Medical \\ Center School of Medicine, New Orleans, USA
}

SUMMARY On-lay lamellar keratoplasty was performed in 29 patients who had keratoconus. Twelve patients ( $>1$ year follow-up) showed an average decrease in keratometry of $9 \cdot 13 \pm 2.02$ (mean \pm SE) D; 6 patients (6-11 months follow-up) showed an average of $10 \cdot 15 \pm 2 \cdot 88 \mathrm{D}$. Visual acuity continued to improve for about one year after surgery. Six patients with best visual acuities of $20 / 20$ before surgery showed an average visual acuity of $20 / 29 \pm 11$ (mean \pm SD) 4 months after surgery; 4 with more than a year of follow-up achieved an average of $20 / 26 \pm 9$. Four patients with $20 / 40$ preoperatively achieved an average of $20 / 63 \pm 33$ four months after surgery; 3 with more than a year of follow-up showed an average of $20 / 38 \pm 13$. All patients with successful grafts can now tolerate contact lenses for daily wear.

On-lay lamellar keratoplasty for the treatment of keratoconus is a modification of the epikeratophakia procedure originally developed by Kaufman and Werblin for the correction of aphakia. ${ }^{12}$ In that technique the Barraquer cryolathe is used to shape a piece of donor cornea as one would a contact lens, and this lenticule is sutured to the surface of the recipient cornea after the recipient epithelium has been removed. The sutures are placed in a shallow, circular, superficial keratectomy that has been trephined in the periphery of the recipient cornea.

For the treatment of keratoconus the plano lamellar graft is sutured tightly across the cone to flatten the protrusion and reinforce the thinned cornea. The plano grafts can be shaped on the cryolathe, as are grafts for refractive surgery. Excellent visual results have been obtained in patients receiving these grafts. $^{2}$ However, the principle of this surgery is applicable even without this complex instrumentation; the grafts can be cut from the donor tissue on the microkeratome or by any lamellar dissection technique.

This form of noninvasive surgery may be preferable for the treatment of moderate to advanced keratoconus, especially in patients who have a history of rejection episodes after corneal transplantation in the

Correspondence to Marguerite B. McDonald, MD, LSU Eye Center, 136 South Roman Street, New Orleans, LA 70112, USA. fellow eye or who have large cones that extend out near the corneoscleral limbus. A previously reported technique $^{3}$ requires dissection of a bed over thin corneal tissue, and the average postoperative visual acuity was no better than $20 / 40 .^{45}$

The first 6 patients who underwent on-lay lamellar keratoplasty were described after 3 to 6 months of follow-up. ${ }^{2}$ We now have a series of 29 patients who have undergone this procedure; 26 have been followed up for more than 6 months and 13 for more than one year.

\section{Subjects and methods}

Twenty-nine patients with keratoconus, who had become unable to wear contact lenses and whose visual acuities could not be corrected with spectacles, received plano lamellar grafts (Table 1). Admission to the study was limited to keratoconus patients with best preoperative visual acuities of $20 / 40$ or better, measured with a hard contact lens. These patients could tolerate the lens for only a few minutes for diagnostic purposes.

The grafts were $0.3 \mathrm{~mm}$ thick. After the donor tissue was shaped on the cryolathe it was lyophilised for storage. Immediately prior to surgery the tissue was rehydrated with balanced salt solution containing $100 \mu \mathrm{g} / \mathrm{ml}$ of gentamicin. The surgical technique has 
Table 1 Twenty-nine patients with keratoconus who received on-lay lamellar keratoplasty grafts

\begin{tabular}{ll}
\hline Follow-up (months) & Number of patients \\
\hline $12-23$ & $13^{*}$ \\
$6-11$ & $13^{+}$ \\
$3-5$ & 2 \\
Less than 3 & 1 \\
Total & 29
\end{tabular}

* One patient was excluded from the tabulation of visual acuity data because she underwent a combined phakoemulsification and on-lay lamellar keratoplasty.

tThree patients were excluded, 2 because of graft failure, and one because of trauma to the graft. Four others were unavailable for refraction and keratometry measurements.

been described. ${ }^{2}$ Grafts $0.5 \mathrm{~mm}$ larger in diameter than the recipient bed were used in the last 23 patients; in the first 6 patients this graft/bed size disparity varied from 0 to $0.5 \mathrm{~mm}$, with one patient receiving a graft $0.2 \mathrm{~mm}$ smaller than the recipient bed. High-water-content, bandage soft contact lenses were used for 3 weeks after surgery to protect the graft and promote re-epithelialisation. Most of the sutures were removed between 3 and 16 weeks after surgery, depending on individual rates of healing. Low doses of corticosteroids $(0 \cdot 1 \%$ dexamethasone sodium phosphate 2 to 4 times a day) were applied topically to the eyes of some patients as needed for the treatment of mild postoperative iritis.

\section{Results}

Of the 26 patients who have been followed up for more than 6 months 8 have been excluded from the tabulation of keratometry values (Table 2 ) and visual acuity data (Table 3 ). Two patients had grafts removed because of chronic epithelial defects. One patient underwent a combined procedure-phakoemulsification for cataract removal and on-lay lamellar keratoplasty for keratoconus-and recovery was therefore delayed. In one patient a limbal blood vessel was mechanically injured, at which time some blood seeped into the interface between the donor tissue and the recipient cornea. The blood developed into a yellow-white interface opacity that is resorbing slowly, and her vision has nearly recovered. Four patients who live some distance from New Orleans are being followed up by their local physicians; we have been told that these patients have excellent vision and can wear contact lenses on a daily basis, but we have no current refractive or keratometric measurements.

Twenty-six of the 29 grafts were completely covered with recipient epithelium within 10 days of surgery; 2 others were removed, as described above, and one
Table 2 Changes in keratometry

\begin{tabular}{lll}
\hline $\begin{array}{l}\text { Time after } \\
\text { surgery } \\
\text { (months) }\end{array}$ & $\begin{array}{l}\text { Number } \\
\text { of } \\
\text { patients }\end{array}$ & $\begin{array}{l}\text { Difference between pre- and } \\
\text { postoperative keratometry } \\
\text { readings (corneal flattening) } \\
\text { (dioptres) }\end{array}$ \\
\hline $\begin{array}{l}\text { M-11 } \\
12\end{array}$ & 6 & $10 \cdot 15 \pm 2 \cdot 88^{*}$ \\
\hline
\end{tabular}

*Mean \pm standard error of the mean.

Table 3 Average best visual acuities of 18 patients with 6 to 23 months of follow-up*

\begin{tabular}{llll}
\hline Preoperative & \multicolumn{3}{l}{ Postoperative (months) } \\
\cline { 2 - 4 } & 4 & 8 & More than 12 \\
\hline $20 / 20$ & $20 / 29 \pm 11+(6) \ddagger$ & $20 / 31 \pm 16(5)$ & $20 / 26 \pm 9(4)$ \\
$20 / 25$ & $20 / 58 \pm 30(6)$ & $20 / 43 \pm 6(6)$ & $20 / 32 \pm 6(3)$ \\
$20 / 30$ & $20 / 30 \pm 4(2)$ & $20 / 20 \pm 0(2)$ & $20 / 20 \pm 0(1)$ \\
$20 / 40$ & $20 / 63 \pm 33(4)$ & $20 / 50 \pm 22(4)$ & $20 / 38 \pm 13(3)$ \\
\hline
\end{tabular}

*Measured with hard contact lens.

†Standard deviation.

¥Number of patients. All 18 patients are included in 4 month followup groups; smaller numbers in succeeding groups indicate portion of first group with longer follow-up.

had a small peripheral graft melt owing to a chronic epithelial defect, which has since healed with no adverse effect on vision.

The average decrease in keratometric measurements obtained in the patients with 6 to 11 months of follow-up was similar to that seen in the group with more than 12 months of follow-up (Table 2). The average regular astigmatism decreased in the patients with more than 12 months of follow-up.

Best visual acuities, measured with a hard contact lens, were well within the range of useful vision 4 months after surgery (Table 3 ), and continued to improve with time. All these patients were former contact lens wearers who had become intolerant of this form of correction. After this operation all have been able to be fitted with hard contact lenses and can wear these lenses on a daily basis.

\section{Discussion}

The advantages of on-lay lamellar keratoplasty for keratoconus are: $(a)$ it is a possible alternative to penetrating keratoplasty for the treatment of extensive cones or eccentric cones with limbal involvement and no central scarring; (b) as with other lamellar graft procedures it may be associated with a reduced incidence of graft rejection; such rejection may be more common in patients who undergo 
bilateral penetrating keratoplasties ${ }^{6} ;(c)$ it is an extraocular procedure; $(d)$ no lamellar dissection of the recipient cornea is necessary; $(e)$ there is little chance of penetration of the anterior chamber, because the thinnest area of the cone is undisturbed; ( $f$ ) the grafts can be cut on the cryolathe, by microkeratome, or by any lamellar dissection technique; $(g)$ preshaped grafts can be lyophilised and stored or shipped, enabling distribution from a central source; and $(h)$ lyophilised grafts require only 20 minutes of rehydration in balanced salt solution and antibiotic before being sutured into place (rehydration can be started as the patient is being draped for surgery).

At first all the epithelium was removed from limbus to limbus to reduce the risk of interface debris when the graft was sewn into place. This procedure led to problems during regrowth of the epithelium in some patients. In the last 8 cases a 0.5 to $1 \mathrm{~mm}$ 'cuff' of
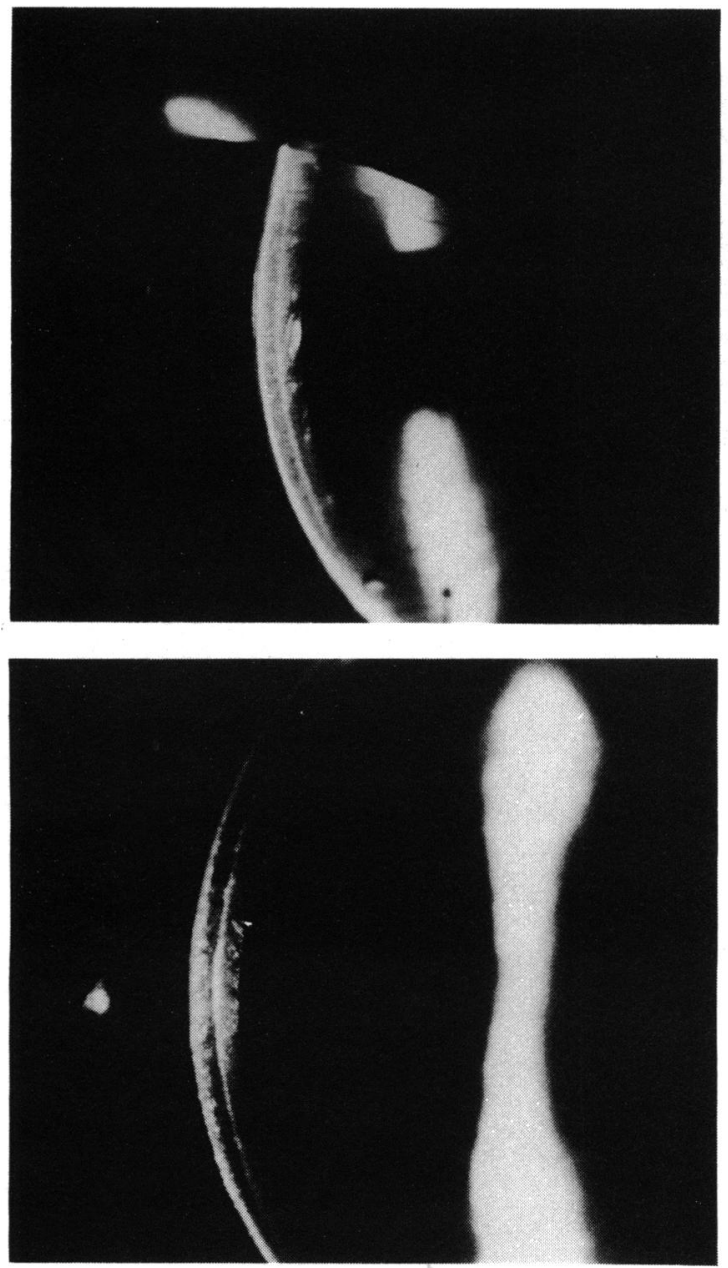

epithelium was left at the corneoscleral limbus, which seemed to encourage faster re-epithelialisation. In our last patient epithelialisation was completed within 3 days of surgery.

Among our earliest patients one had an anterior chamber paracentesis prior to suturing and another had received an elliptical graft in an attempt to correct a large amount of preoperative cylinder. These 2 patients had larger amounts of residual astigmatism, probably because the softened eye was sutured less symmetrically in the first case, and the elliptical graft resulted in overcorrection in the second case.

Postoperative vision in the first 3 months was limited, presumably because the sutures were still in place and the grafts were not yet repopulated with recipient keratocytes. Many deep folds were noted in the Descemet's membrane of the recipient cornea at the site where the cone was flattened (Fig. 1), but

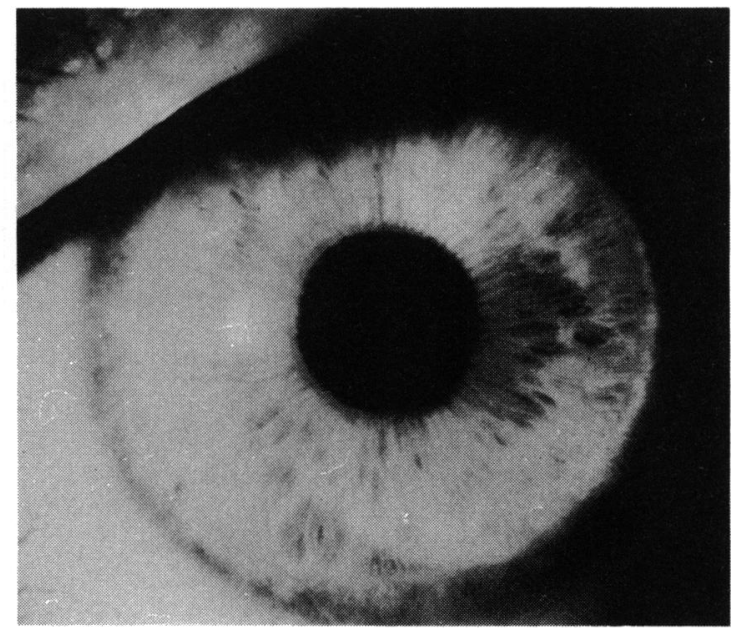

Fig. 1 Top left: On-lay lamellar graft 8 days after surgery. Note bandage soft contact lens, suture at 6.00 o'clock, and folds in the Descemet's membrane of the recipient cornea. Top right: same eye, 51/2 months after surgery.

Bottom left: same as top right, slit-lamp photograph. 
these central folds disappeared by 6 weeks after surgery. Approximately 4 months after surgery useful vision returned and the patients were able to wear contact lenses on a daily basis.

To investigate whether the time needed for visual recovery after on-lay lamellar keratoplasty can be shortened we intend to compare fresh donor tissue cut with a microkeratome with lyophilised, lathe-cut grafts. We have also recently begun dehydrating the donor tissue mechanically in the corneal press before lathing. The dehydration procedure eliminates much of the swelling observed in the out-of-date donor tissue used in this surgery; the donor tissue is reduced to its normal, nonepithelialised thickness of 0.475 $\mathrm{mm}$, and the collagen fibres resume a more normal pattern. Although our studies are not complete, our clinical impression is that the later patients, who received donor tissue that had been dehydrated, are recovering useful vision more rapidly.

Photokeratoscope (corneascope) photographs are being taken of patients undergoing this procedure to measure both regular and irregular astigmatism more accurately before and after surgery.

A large multicentre prospective clinical study is under way to compare penetrating keratoplasty with on-lay lamellar keratoplasty for the treatment of moderately advanced keratoconus. The patients reported here, however, either were operated on before the study began, or were not randomised into the study because of a history of graft rejection in the fellow eye. The results in the patients in the randomised prospective study will be reported by the group after sufficient follow-up and statistical analyses are completed.

This work was supported in part by USPHS grants EY02580, EY07073, and EY02377 from the National Eye Institute, Bethesda, Maryland, and an unrestricted grant from Research to Prevent Blindness, Inc., New York City.

\section{References}

1 Kaufman HE. The correction of aphakia. Am J Ophthalmol 1980; · 89: $1-10$.

2 Kaufman HE, Werblin TP. Epikeratophakia for the treatment of keratoconus. Am J Ophthalmol 1982; 93: 342-7.

3 Malbran E. Lamellar keratoplasty and keratoconus. In: King JH, McTigue JW, eds. The cornea-world congress. Washington, DC: Butterworths, 1965: 511.

4 Wood TO. Lamellar transplants and keratoconus. Am J Ophthalmol 1977; 83: 543-5.

5 Polack FM. Lamellar keratoplasty. Malbran's 'peeling-off' technique. Arch Ophthalmol 1971; 86: 293-5.

6 Donshik PC, Cavanagh HD, Boruchoff SA, Dohlman CH. Effect of bilateral and unilateral grafts on the incidence of rejection in keratoconus. Am J Ophthalmol 1979; 87: 823-6. 